\title{
Vacinação contra influenza em crianças infectadas pelo HIV: alterações imunológicas e na carga viral
}

\author{
Influenza vaccination in HIV infected children: immunologic and viral load changes
}

\author{
Aroldo P. de Carvalho ${ }^{1}$, Luiz Carlos Dutra ${ }^{2}$, Edward Tonelli ${ }^{3}$
}

\section{Resumo}

Objetivo: verificar se a vacinação contra influenza em crianças infectadas pelo HIV aumentaria a carga viral e reduziria os linfócitos T CD4+, conseqüentes à ativação da imunidade com antígenos dependentes do linfócito $\mathrm{T}$.

Métodos: estudo prospectivo descritivo, com 51 crianças infectadas pelo HIV, vacinadas contra influenza em 1999, em Florianópolis, Brasil. Coletaram-se amostras de sangue no dia da vacinação, 14 a 20 e 60 a 90 dias após, para determinação dos níveis da carga viral do HIV e de linfócitos T CD4+. A análise estatística constou dos testes ANOVA de Friedman, $t$ de Student para amostras dependentes, Correção de Bonferroni e Wilcoxon.

Resultados: a média de idade foi de 6,08 anos (1 a 12,9 anos). A mediana da contagem de linfócitos T CD4+ no dia da vacinação e nos dois momentos subseqüentes foi de 789,645 e 768 células $/ \mathrm{mm}^{3}$. Observou-se redução significativa na contagem de linfócitos $\mathrm{T}$ $\mathrm{CD} 4+$ entre a primeira e a segunda determinação $(\mathrm{p}=0,0001$, teste de Wilcoxon), o mesmo não ocorrendo entre a primeira e a terceira . Não houve diferença significativa nas porcentagens de linfócitos TCD4+ entre a primeira aferição e a segunda. A mediana da carga viral em $\log _{10}$ cópias/ml foi de 4,38, 4,30 e 4,25, nos três momentos, respectivamente. Oito de 44 pacientes $(18,2 \%)$ evidenciaram elevação $\geq 0,5$ $\log _{10}$ cópias/ml na carga viral entre a primeira e segunda aferição, quatro dos quais retornaram aos níveis basais na terceira.

Conclusões: não se observou alteração significativa na porcentagem de linfócitos T CD4+, apesar de ocorrer elevação da carga viral do HIV, de forma transitória, após vacinação contra influenza. Recomenda-se uma certa prudência na aplicação da vacina contra influenza para as crianças com condição clínica e imunológica não estável, principalmente se essas não estiverem sob terapêutica antiretroviral eficaz.

J Pediatr (Rio J) 2003;79(1):29-40: influenza, vacina contra influenza, infecção pelo HIV, carga viral do HIV, níveis de linfócitos T CD4+.

\begin{abstract}
Objective: to identify whether influenza immunization in HIV infected children could increase HIV viral load and decrease CD4+ lymphocytes count as a consequence of the response induced by a $\mathrm{T}$ cell-dependent antigen

Methods: prospective, descriptive study, with 51 HIV infected children, vaccinated against influenza in 1999, in Florianópolis, Brazil. Blood samples were collected at three different moments: on the immunization day; between 14 and 20 days later; between 60 and 90 days later. Plasma levels of HIV viral load and CD4+ lymphocytes count were determined. Friedman ANOVA test, Student t-test for dependent samples, Bonferroni correction, and Wilcoxon matched test were performed for statistic analysis.
\end{abstract}

Results: children's mean age was 6.08 years (1 to 12.9 years). The medians of CD4+ lymphocyte count on vaccination day and at the other two moments were 789,645 and 768 cells $/ \mathrm{mm}^{3}$, respectively. A significant reduction was observed in the CD4+ lymphocyte count between the first and the second analyses, but the same did not happen between the first and the third analyses. There was no significant difference of CD4+ lymphocyte percentage between the first and the second analyses. The median of HIV viral load values in $\log _{10}$ copies/ml was $4.38,4.30$ and 4.25 , at the three moments respectively. Eight out of 44 patients $(18.2 \%)$ showed increase $\geq 0.5$ $\log _{10}$ copies/ml in HIV viral load between the first and the second analyses and among these, four returned to levels close to their base levels in the third analysis.

Conclusion: there was no significant change in the CD4+ lymphocyte percentage, in spite of a transitory increase in HIV viral load after influenza vaccination. Caution should be used when administering vaccine against flu to children with no stable clinical and immunological conditions, mainly if they are not under effective anti-retroviral therapeutics.

JPediatr (Rio J) 2003;79(1):29-40: influenza, influenza vaccine, HIV infection, HIV-1 viral load, CD4 T lymphocyte.

1. Doutor em Medicina, Área de Concentração em Pediatria pela UFMG. Professor Adjunto de Pediatria da UFSC e da UNIVALI. Infectologista Pediatra do Hospital Infantil Joana de Gusmão, Florianópolis.

2. Bioquímico do Setor de Virologia do Laboratório Central de Santa Catarina.

3. Professor Emérito da Faculdade de Medicina da UFMG. Professor Titular e Livre Docente de Pediatria da UFMG (aposentado). Orientador do Curso de PósGraduação da Faculdade de Medicina da UFMG. Consultor do CNPQ.

Artigo submetido em 22.01.02, aceito em 06.11.02. 
As infecções respiratórias representam uma preocupação constante para os pacientes portadores de enfermidades imunodepressoras, sendo freqüentes em portadores de Aids. Alguns estudos têm demonstrado que mais de $80 \%$ desses pacientes desenvolvem infecção pulmonar em algum estágio da doença ${ }^{1}$. As crianças infectadas pelo HIV têm um aumento na suscetibilidade para infecções respiratórias virais e bacterianas, havendo relatos de casos de infecções persistentes pelos vírus influenza ${ }^{2}$.

A ativação ou não do linfócito T CD4+, principal célula hospedeira da infecção pelo HIV, mediante a estimulação por antígenos exógenos, mitógenos, ou certas citoquinas, constitui o ponto crucial para que se produza um estado infeccioso, ou para que o vírus permaneça em estado latente, com ausência de ativação celular e restrição do ciclo replicativo ${ }^{3-5}$.

As infecções intercorrentes expõem as células $\mathrm{T}$ à presença de antígenos novos ou já conhecidos, podendo levar à ativação dessas células, inclusive das células $\mathrm{T}$ infectadas pelo HIV quiescentes. Esses eventos poderiam ocasionar um aumento na replicação do HIV e acelerar o curso da doença 6 .

A vacinação por agentes que possuem antígenos dependentes do linfócito $\mathrm{T}$, como é o caso da vacina contra a influenza com vírus inativados, pode levar, teoricamente, a um aumento na replicação do HIV, com infecção de novas células, resultando em uma maior destruição celular, podendo, por isso, ser até prejudicial ao organismo ${ }^{7-9}$.

A carga viral dos pacientes pediátricos infectados pelo HIV evidencia valores bem mais elevados, especialmente nos primeiros anos de vida, nem sempre se correlacionando com importantes alterações imunológicas, ou com exuberância na apresentação clínica ${ }^{10-12}$.

Desde o início da década de 1990, as vacinas contra o vírus influenza têm sido incluídas entre os imunobiológicos recomendados para os pacientes portadores do HIV ${ }^{13}$. No entanto, alguns estudos, tanto em adultos quanto em crianças, têm demonstrado que essas vacinas podem levar a uma ativação na replicação do HIV, com um aumento na carga viral e uma diminuição na população de linfócitos T CD4+. Porém, as observações mais consistentes parecem demonstrar que, quando ocorrem, essas alterações são transitórias, não produzindo conseqüências danosas ao organismo, sendo os benefícios maiores do que os riscos ${ }^{14,15}$.

O Ministério da Saúde do Brasil, através da Coordenação Nacional de Doenças Sexualmente Transmissíveis e Aids (CN-DST/Aids) e do Comitê Assessor para Terapia Anti-Retroviral em Crianças Infectadas pelo HIV, não fazia, até o ano 2000, qualquer menção à indicação da vacina contra a influenza para as crianças portadoras do HIV, tendo sido incluída no ano 2001. Essa indicação faz parte das normas dos centros de referência para imunobiológicos especiais (CRIE) do Programa Nacional de Imunizações (PNI) do Ministério da Saúde do Brasil ${ }^{16-18}$.
O objetivo do presente estudo foi avaliar os efeitos da estimulação imunológica induzida pela vacina contra o vírus influenza em crianças portadoras do HIV, visando observar a ocorrência de um possível aumento na replicação do vírus, com elevação na carga viral, e verificar a ocorrência de alterações imunológicas, representadas por uma depleção na população de linfócitos T CD4+.

\section{Métodos}

Realizou-se um estudo prospectivo descritivo a partir do ano de 1999, na Universidade Federal de Minas Gerais (UFMG), Belo Horizonte, Brasil, com uma coorte de crianças infectadas pelo HIV, acompanhadas longitudinalmente durante um período de 12 meses após o recebimento da vacina contra influenza, no Serviço de Assistência Especializada (SAE) para o atendimento de crianças portadoras do vírus no Hospital Infantil Joana de Gusmão (HIJG), Florianópolis, Santa Catarina, Brasil, em colaboração com o Laboratório Central do Estado de Santa Catarina (LACEN), Universidade Federal de Santa Catarina (UFSC) e Laboratório Médico Ciência de Florianópolis.

Foram obtidas amostras de sangue antes da administração da vacina para quantificação no sangue periférico, considerada basal, da carga viral do HIV e para a avaliação dos níveis de linfócitos T CD4+, através de sua contagem absoluta e porcentagem. Esta avaliação inicial serviu de controle para as aferições posteriores, as quais foram repetidas dentro de um período de 14 a 20 dias após a vacina, quando provavelmente se esperaria a resposta de anticorpos normalmente desejada da imunização, com o pico nos níveis de imunoglobulina $\mathrm{G}$, e após 60 a 90 dias, para verificar se a carga viral e o nível da subpopulação linfocitária haviam retornardo aos valores basais, caso tivessem sofrido alterações.

Optou-se pela não inclusão de um grupo controle, para o qual não seria aplicada a vacina, uma vez que a recomendação do Ministério da Saúde do Brasil e do Centro de Controle e Prevenção de Doenças (CDC), dos EUA, para a aplicação da vacina contra influenza para indivíduos portadores de infecção pelo HIV poderia tornar não ético o estudo ${ }^{13,17}$.

O estudo foi submetido e aprovado pelo Comitê de Ética em Pesquisa com Seres Humanos da UFSC, processo 027/ 99, registrado na Comissão Nacional de Ética em Pesquisa (CONEP) e pelo Comitê de Ética em Pesquisa da UFMG, parecer 228/2001.

O consentimento livre e esclarecido dos pais ou responsáveis legais pela criança foi obtido por um profissional de saúde não envolvido diretamente na pesquisa, esclarecendo-se todos os detalhes da mesma.

O cálculo do tamanho da amostra não foi possível de ser realizado pela escassez de dados de literatura, optando-se por uma amostra de conveniência, maior do que as amostras observadas em estudos anteriores, factível com o serviço 
onde foi desenvolvido o estudo. Essa amostra poderia permitir ou não se chegar a certas conclusões.

As crianças foram selecionadas com base nos seguintes critérios de inclusão: (a) comprovadamente infectadas pelo HIV, segundo os critérios para o diagnóstico do Ministério da Saúde ${ }^{19}$; (b) idade igual ou superior a seis meses, pois a vacinação contra influenza está indicada somente a partir dessa idade, limitando-se à faixa etária até os 13 anos; (c) condições clínicas ou imunológicas estáveis, caso não estivessem em uso de terapêutica ARV; (d) caso em uso de esquemas terapêuticos anti-retrovirais, eles deveriam ter sido instituídos há mais de três meses, e os pacientes deveriam encontrar-se em condições clínicas e imunológicas estáveis; (e) disponibilidade para retornar entre 14 e 20 dias após a aplicação da vacina e/ou de 60 a 90 dias após, para a obtenção da segunda e terceira amostras de sangue; (f) não terem sido imunizadas contra influenza em anos anteriores.

Os pacientes foram excluídos do estudo caso se encontrassem em algumas das situações abaixo relacionadas: (a) recebimento de imunoglobulina endovenosa até 60 dias antes da aplicação da vacina contra influenza; (b) modificação da terapêutica ARV há menos de 90 dias; (c) apresentação de infecções agudas associadas há menos de 90 dias da aplicação da vacina e durante o período de coleta das amostras de sangue; (d) utilização de outras vacinas há menos de 60 dias, ou que tenha indicação de receber simultaneamente outras vacinas; (e) carga viral inicial acima de 1.000 .000 de cópias $/ \mathrm{ml}$, equivalente a $6,0 \log _{10}$ cópias $/ \mathrm{ml}$; (f) não concordância dos responsáveis para a inclusão de seu filho(a) no estudo, já no início, ou em qualquer momento de sua execução.

Os pacientes foram divididos em faixas etárias de zero a um ano, um ano e um mês a cinco anos e maiores de cinco anos até 12 anos e 11 meses. Essas faixas são correspondentes aos padrões de valores de linfócitos T CD4+ por grupo etário, considerados na classificação imunológica ${ }^{20}$.

O quadro clínico dos pacientes e a classificação, segundo os critérios clínicos e imunológicos do CDC de $1994^{20}$, foram obtidos no momento da inclusão da criança no estudo, e os esquemas da terapêutica ARV que os pacientes vinham recebendo foram obtidos avaliando-se possíveis interferências na adesão aos esquemas.

As amostras foram coletadas em tubos contendo anticoagulante EDTA, sendo que de uma parte foi obtido o soro, o qual foi acondicionado em tampão de lise, para realização do teste de quantificação da carga viral do HIV, e o restante serviu para a avaliação de linfócitos T CD4+.

A metodologia para a quantificação da carga viral foi o ensaio de amplificação baseado na seqüência de ácido nucléico (nucleic acid sequence based assay - NASBA, NUCLISENS ${ }^{\mathrm{TM}} H I V-1 Q T$ ), produzido pela Organon Tekni$\mathrm{ka}^{21}$, recomendada pelo Ministério da Saúde do Brasil ${ }^{22}$.

Foram valorizadas alterações na carga viral iguais ou maiores do que cinco vezes, ou $0,7 \log _{10}$ cópias $/ \mathrm{ml}$ para as crianças com idade igual ou menor do que dois anos, e de pelo menos três vezes ou $0,5 \log _{10}$ cópias $/ \mathrm{ml}$ para as maiores de dois anos ${ }^{16,23}$.

Os exames para a obtenção dos valores absolutos e percentuais de linfócitos T CD4+ foram realizados pela técnica da citometria de fluxo, conforme descrição apresentada em manual específico do Ministério da Saúde do Brasil $^{24}$.

Consideraram-se como alterações imunológicas relevantes as mudanças de categoria imunológica de acordo com o sistema de classificação do CDC (CDC, 1994) ${ }^{20}$, valorizando-se uma redução maior do que $20 \%$ em relação à aferição anterior e, para as crianças já na categoria imunológica 3 (CD4 < 15\%), uma diminuição de cinco ou mais percentuais, segundo o CDC (1998) ${ }^{23}$.

A vacina contra influenza aplicada foi liberada pelo PNI, através dos CRIE de Santa Catarina para indivíduos portadores do HIV ${ }^{17}$. Esta vacina de vírus fragmentados foi produzida pela Pasteur Mérieux Connaught, cepas 98$99^{25}$, sendo constituída por antígenos análogos a A/Sydney/5/97 (H3N2), A/Beijing/262/95 (H1N1), B/Beijing/ 184/93, estando de acordo com as recomendações da Organização Mundial da Saúde (OMS) para a temporada de 1998-1999, e do CDC dos EUA para a temporada 1999$2000^{26}$.

As crianças entre seis e 35 meses de idade receberam a vacina em duas doses de $0,25 \mathrm{ml}$, e entre 36 meses de idade até oito anos, duas doses de $0,5 \mathrm{ml}$, sendo o intervalo entre as doses de quatro a seis semanas, e, a partir dos nove anos de idade, foi aplicada dose única de $0,5 \mathrm{ml}$. Estas indicações estão de acordo com as recomendações do fabricante e do Ministério da Saúde do Brasil ${ }^{17}$.

Os dados foram arquivados em um questionário do programa EPI-Info ${ }^{27}$ e no Excel $2000^{28}$, e transportados também para o programa Statistica versão $98^{29}$, efetuandose a análise estatística a partir desses programas.

A estratégia adotada para a análise estatística foi inicialmente de comparações múltiplas, verificando-se, simultaneamente, os três momentos de aferição, com o emprego do teste não paramétrico ANOVA de Friedman. Corroborando os achados do teste ANOVA de Friedman, realizouse a análise das variáveis duas a duas, entre a primeira e segunda e primeira e terceira aferições. Utilizou-se o teste paramétrico $t$ de Student para dados pareados, para a comparação entre os valores percentuais de linfócitos $\mathrm{T}$ CD4+ e carga viral em $\log _{10}$ cópias/ml, por apresentarem distribuição normal, e o teste não paramétrico de Wilcoxon para a comparação entre os valores absolutos de linfócitos T CD4+ e carga viral em cópias/ml, cujos valores não apresentavam distribuição normal.

O nível de significância estatística adotado no estudo foi de $5 \%$. No entanto, nas comparações entre as medidas no primeiro e segundo momento e entre o primeiro e terceiro momento, o nível de significância estatística foi especificado por meio da correção de Bonferroni, ou seja, $\alpha / \kappa$, onde 
$\alpha$ é 5\%, nível de significância original, e $\kappa$ é o número de comparações realizadas.

\section{Resultados}

Das 133 crianças que receberam a vacina contra influenza, 51 foram selecionadas para o estudo em ordem de atendimento, por estarem de acordo com os critérios de inclusão.

As amostras de sangue foram obtidas no dia da vacinação em todas as 51 crianças, sendo que para a carga viral do HIV foi possível a obtenção da segunda amostra em 44, enquanto para a terceira, coletou-se de 51 pacientes. A carga viral não foi detectada, nos três momentos de aferição, em uma criança. Eliminou-se, para a análise estatística, a terceira amostra de três pacientes, uma vez que foi iniciada terapêutica anti-retroviral.

A quase totalidade das crianças contraiu a infecção pelo HIV por transmissão vertical, sendo que esse mecanismo de contágio não foi possível ser confirmado em apenas dois pacientes $(3,9 \%)$, por ausência de informações a respeito de suas mães.

As características da população estudada como sexo, faixa etária, classificação clínica e imunológica e utilização de anti-retrovirais pode ser visualizada na Tabela 1.

Tabela 1 - Distribuição das 51 crianças com infecção pelo HIV vacinadas contra influenza, de acordo com o sexo, a faixa etária, a classificação clínica e imunológica $\left(\mathrm{CDC} / 1994^{20}\right)$ e a utilização de anti-retrovirais HIJG, Florianópolis, SC

\begin{tabular}{lcc}
\hline Característica & $\mathbf{n}$ & \% \\
\hline Faixa etária & & \\
0 - 1 ano & 1 & 2,0 \\
1 ano e 1 mês -5 anos & 20 & 39,2 \\
5 anos e 1 mês - 12 anos e 11 meses & 30 & 58,8 \\
Sexo & & \\
Masculino & 28 & 54,9 \\
Feminino & 23 & 45,1 \\
Classificação & & \\
A1 & 15 & 29,4 \\
A2 & 7 & 13,8 \\
A3 & 2 & 3,9 \\
B1 & 9 & 17,7 \\
B2 & 4 & 7,8 \\
C1 & 4 & 7,8 \\
C2 & 6 & 11,8 \\
C3 & 4 & 7,8 \\
Anti-retrovirais & & \\
AZT+DDI & 26 & 51,0 \\
AZT+3TC & 5 & 9,8 \\
D4T+3TC+RTV & 5 & 9,8 \\
D4T+3TC & 3 & 5,9 \\
Nenhum & 7 & 13,7 \\
Outros & 5 & 9,8 \\
& & \\
\hline & &
\end{tabular}

Os valores absolutos da contagem de linfócitos T CD4+ e a porcentagem no dia da aplicação da vacina e nas duas aferições subseqüentes podem ser visualizados na Tabela 2. Observou-se diferença estatisticamente significativa nos valores absolutos entre os três momentos de aferição $(\mathrm{p}=0,002)$, o mesmo não se observando nas porcentagens $(\mathrm{p}=0,45)$.

A Tabela 3 mostra a avaliação da carga viral do HIV nos três momentos, não se observando diferença estatisticamente significativa dos valores em número de cópias/ml $(\mathrm{p}=0,99)$, assim como em $\log _{10}$ cópias/ml $(\mathrm{p}=0,98)$.

Os valores em percentuais de linfócitos T CD4+ se reduziram em níveis consideráveis, ou seja, uma redução de $20 \%$ em relação ao valor inicial ou de cinco ou mais percentuais caso a criança já se encontrasse na categoria imunológica 3, 14 a 20 dias após a vacina, em 14 (31,8\%) das 44 crianças nas quais puderam ser obtidas as duas aferições, aumentaram em nove $(20,5 \%)$ e permaneceram praticamente inalterados em $21(47,7 \%)$.

Entre as 14 crianças que evidenciaram uma redução significativa na porcentagem de linfócitos T CD4+ entre a primeira e segunda aferição, obteve-se a terceira determinação em 13 , sendo que dessas, cinco $(38,5 \%)$ permaneceram com redução considerável, quatro $(30,8 \%)$ apresentaram um retorno a valores próximos aos basais, e em três $(23,1 \%)$ houve um aumento considerável em relação aos níveis da primeira determinação, para duas das quais houve introdução de esquema ARV.

Entre os sete pacientes que não estavam utilizando qualquer esquema de medicamentos $\mathrm{ARV}$, quatro $(57,1 \%)$ evidenciaram uma redução valorizável nos níveis de linfócitos T CD4+ entre a primeira e a segunda determinações, sendo que em um paciente não se obteve esse dado. Essa redução se manteve na terceira aferição em um paciente $(14,3 \%)$, não foi determinada em outro e aumentou em dois $(28,6 \%)$, para os quais foi iniciado esquema de terapêutica ARV.

Entre os 44 pacientes nos quais foi possível obter a avaliação dos níveis de carga viral, tanto no momento da aplicação da vacina contra a influenza quanto após 14 a 20 dias, em $31(70,4 \%)$ não se observou alteração considerável (igual ou superior a $0,5 \log _{10}$ cópias/ml para os maiores de dois anos de idade e igual ou superior a $0,7 \log _{10}$ cópias $/ \mathrm{ml}$ para aqueles com idade igual ou menor de dois anos), em oito $(18,2 \%)$ se observou uma elevação considerável, e em cinco pacientes $(11,4 \%)$, uma redução.

Dos oito pacientes com aumento considerável, em quatro $(50,0 \%)$ os valores da carga viral na terceira determinação, de 60 a 90 dias após, retornaram a níveis inclusive inferiores aos iniciais, sendo que em um deles houve introdução de terapêutica ARV. A carga viral permaneceu com aumento substancial em três $(37,5 \%)$ das oito crianças, e em uma $(12,5 \%)$ o nível se tornou equivalente ao inicial.

Entre os sete pacientes que não vinham recebendo qualquer medicamento ARV, observou-se aumento consi- 
Tabela 2 - Contagem absoluta e em percentuais de linfócitos T CD4+ no momento da aplicação da vacina contra influenza, 14 a 20 dias e 60 a 90 dias após, em crianças portadoras de infecção pelo HIV - HIJG, Florianópolis, SC

\begin{tabular}{|c|c|c|c|c|}
\hline \multirow[b]{2}{*}{ Linfócitos T CD4+ } & \multicolumn{3}{|c|}{ Período em relação à aplicação da vacina } & \multirow[b]{2}{*}{$\mathbf{p}^{*}$} \\
\hline & Aplicação & 14 a 20 dias & 60 a 90 dias & \\
\hline Número de células $/ \mathrm{mm}^{3}$ & $\mathrm{n}=51$ & $\mathrm{n}=49$ & $\mathrm{n}=46$ & $\mathrm{n}=40$ \\
\hline Mínimo e máximo & $135-2.656$ & $84-2.550$ & $140-2.616$ & \\
\hline Mediana & 789 & 645 & 768 & 0,002 \\
\hline Média & 924 & 814 & 853 & \\
\hline Desvio padrão & 610 & 571 & 568 & \\
\hline Valor percentual & $\mathrm{n}=48$ & $\mathrm{n}=46$ & $\mathrm{n}=40$ & $\mathrm{n}=34$ \\
\hline Mínimo e máximo & $7,6-44,3$ & $3,2-53,5$ & $5,7-59,6$ & \\
\hline Mediana & 25,2 & 26,0 & 26,1 & 0,45 \\
\hline Média & 26,5 & 25,5 & 26,3 & \\
\hline Desvio padrão & 8,7 & 10,6 & 10,4 & \\
\hline
\end{tabular}

* Teste ANOVA de Friedman

derável na carga viral entre a primeira e segunda aferições em apenas um $(14,3 \%)$, sendo que os níveis permaneceram estáveis em relação aos iniciais nas outras seis crianças $(85,7 \%)$.

A comparação entre a porcentagem de linfócitos $\mathrm{T}$ CD4+ no dia da aplicação da vacina e 14 a 20 dias após evidenciou uma redução não estatisticamente significativa na porcentagem $(\mathrm{p}=0,22)$ nos 44 pacientes com os dados disponíveis nos dois momentos, o mesmo ocorrendo entre o primeiro e o terceiro momento de aferição, 60 a 90 dias após a aplicação da vacina $(\mathrm{p}=0,75)$, nas 36 crianças com o dado disponível. Essa comparação foi realizada por meio do teste paramétrico $t$ de Student para amostras pareadas, utilizando-se a correção de Bonferroni, isto é, para o nível de significância corrigido igual a 2,5\% (Figura 1).

Já na avaliação da contagem absoluta de linfócitos $\mathrm{T}$ CD4+, nos 49 pacientes com os dados disponíveis na primeira e segunda aferições, observa-se uma redução estatisticamente significativa ( $\mathrm{p}=0,0001)$, empregando-se o teste não paramétrico de Wilcoxon para amostras dependentes, com nível de significância corrigido de 2,5\%. A comparação dessa variável entre a primeira e a terceira

Tabela 3 - Carga viral do HIV em número e $\log _{10}$ cópias/ml no dia da aplicação da vacina contra influenza, 14 a 20 dias e 60 a 90 dias após, em 51 crianças portadoras de infecção pelo HIV - HIJG, Florianópolis, SC

\begin{tabular}{|c|c|c|c|c|}
\hline \multirow[b]{2}{*}{ Carga viral do HIV } & \multicolumn{3}{|c|}{ Período em relação à aplicação da vacina } & \multirow[b]{2}{*}{$\mathbf{p}^{*}$} \\
\hline & Aplicação & 14 a 20 dias & 60 a 90 dias & \\
\hline Número de cópias/ml & $\mathrm{n}=51$ & $\mathrm{n}=44$ & $\mathrm{n}=48$ & $\mathrm{n}=40$ \\
\hline Mínimo e máximo & $<80-490.000$ & $<80-390.000$ & $<80-230.000$ & \\
\hline Mediana & 24.500 & 20.000 & 18.000 & 0,99 \\
\hline Média aritmética & 66.778 & 68.599 & 47.781 & \\
\hline Desvio padrão & 103.112 & 99.214 & 60.811 & \\
\hline $\log _{10}$ cópias $/ \mathrm{ml}$ & $\mathrm{n}=51$ & $\mathrm{n}=44$ & $\mathrm{n}=48$ & \\
\hline Mínimo e máximo & $<2,0-5,69$ & $<2,0-5,59$ & $<2,0-5,36$ & \\
\hline Mediana & 4,38 & 4,30 & 4,25 & 0,98 \\
\hline Média geométrica & 4,24 & 4,16 & 4,13 & \\
\hline
\end{tabular}

*Teste ANOVA de Friedman 

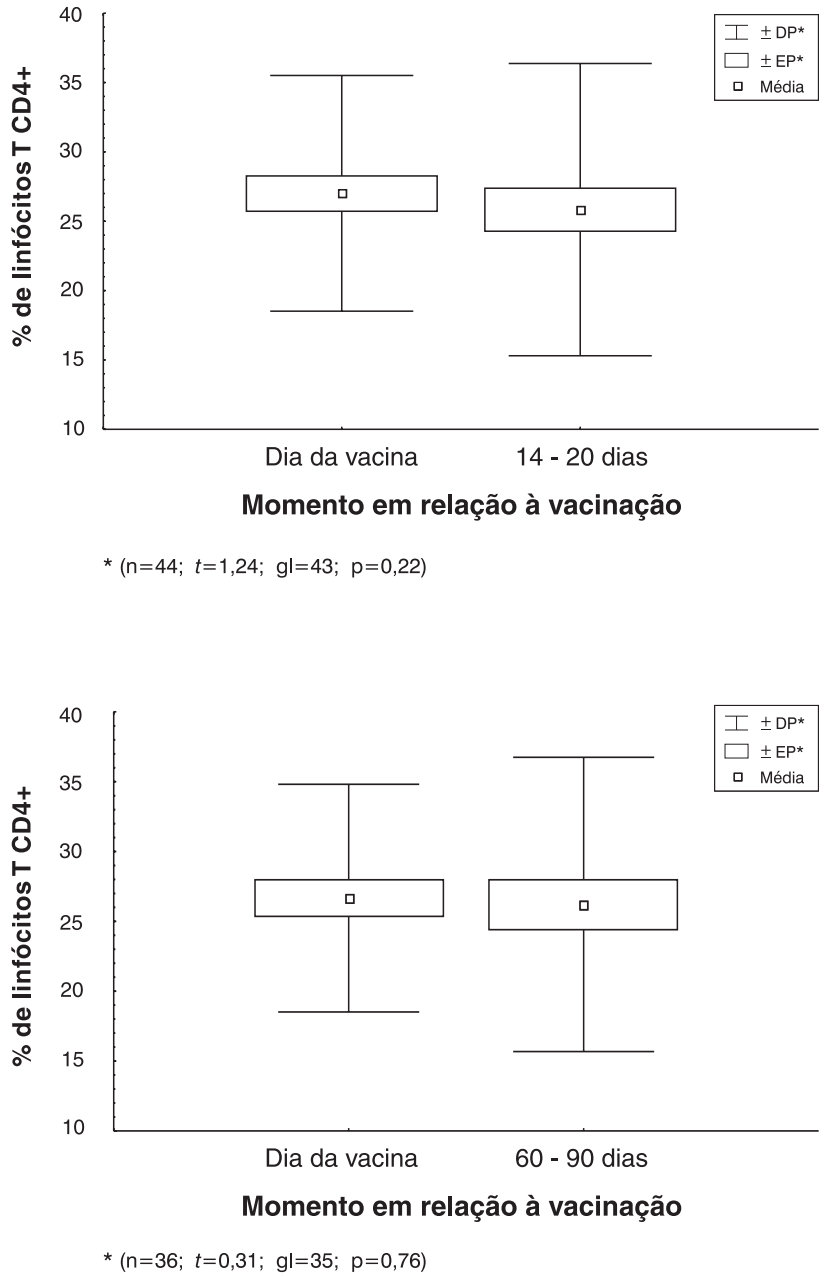

* $\mathrm{n}=$ número de casos; $t=t$ de Student; $g \mathrm{l}=$ graus de liberdade; $\mathrm{DP}=$ desvio padrão; EP= erro padrão

Figura 1 - Comparação entre a porcentagem de linfócitos $\mathrm{T}$ CD4+ no dia da vacinação contra influenza e após 14 a 20 e entre o dia da vacinação e após 60 a 90 dias (Teste $t$ de Student para amostras dependentes) HIJG, Florianópolis, SC

aferição nos 42 pacientes com o dado disponível, utilizando-se o mesmo método, não mais demonstra uma diferença estatisticamente significativa $(\mathrm{p}=0,16)$ (Figura 2).

A comparação dos valores da carga viral do HIV em $\log _{10}$ cópias/ml realizada separadamente entre a avaliação inicial e a avaliação de 14 a 20 dias após, por meio do teste $t$ de Student para amostras pareadas, utilizando-se a Correção de Bonferroni, não demonstrou diferença estatisticamente significativa $(\mathrm{p}=0,69)$ entre os 43 pacientes com o dado disponível. O mesmo ocorrendo quando se comparou o momento inicial com a avaliação de 60 a 90 dias após $(p=0,34)$ entre as 47 crianças nas quais foi possível obter os valores nesses dois momentos (Figura 3 ).
O teste não paramétrico de Wilcoxon para amostras pareadas, utilizado para comparar os valores da carga viral em número de cópias/ml, também não evidenciou diferença estatisticamente significativa entre a primeira e segunda aferição $(\mathrm{p}=0,81)$ nas 43 crianças com essa variável disponível nos dois momentos, não se observando diferença também entre a primeira e terceira aferição $(\mathrm{p}=0,59)$ entre os 47 pacientes com os dados disponíveis (Figura 4).

A combinação de medicamentos ARV não foi modificada até 12 meses após a aplicação do imunobiológico em 41 crianças $(80,4 \%)$.

Dos sete pacientes que não estavam utilizando qualquer esquema ARV, iniciou-se o tratamento em quatro $(57,1 \%)$.
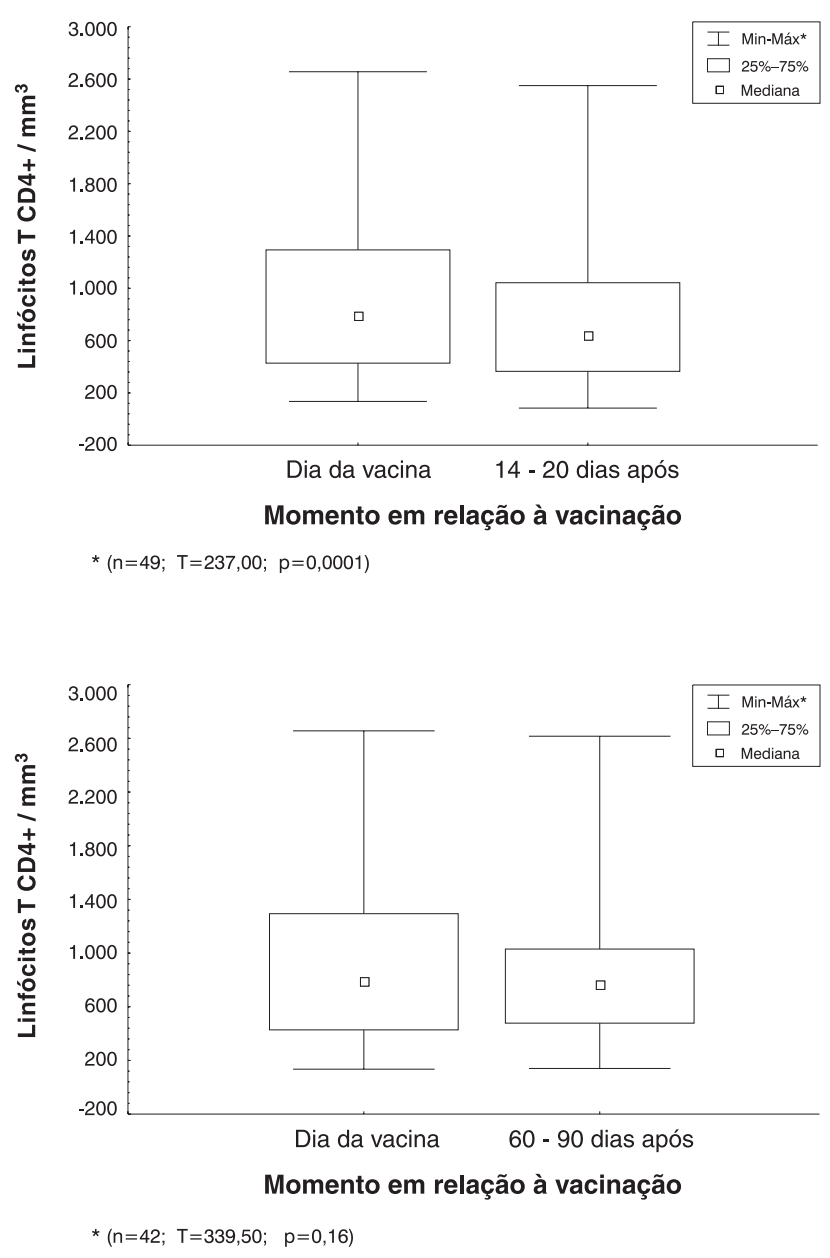

*n=número de casos; $\mathrm{T}=$ teste de Wilcoxon; mín.= mínimo; máx.= máximo.

Figura 2 - Comparação entre os valores absolutos de linfócitos T CD4+ no dia da vacinação contra influenza, e após 14 a 20, e entre o dia da vacinação e após 60 a 90 dias (Teste não paramétrico de Wilcoxon para amostras pareadas) - HIJG, Florianópolis, SC 


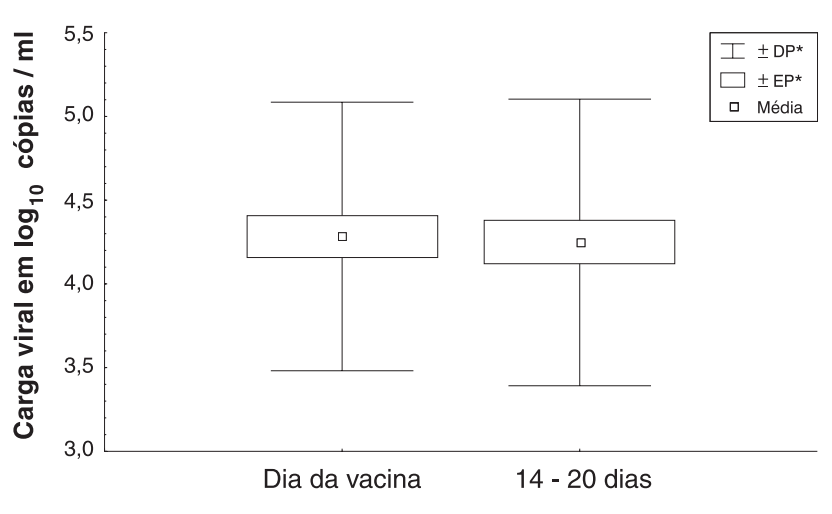

Momento em relação à vacinação

* $(\mathrm{n}=43 ; t=0,40 ; \mathrm{gl}=42 ; \mathrm{p}=0,69)$

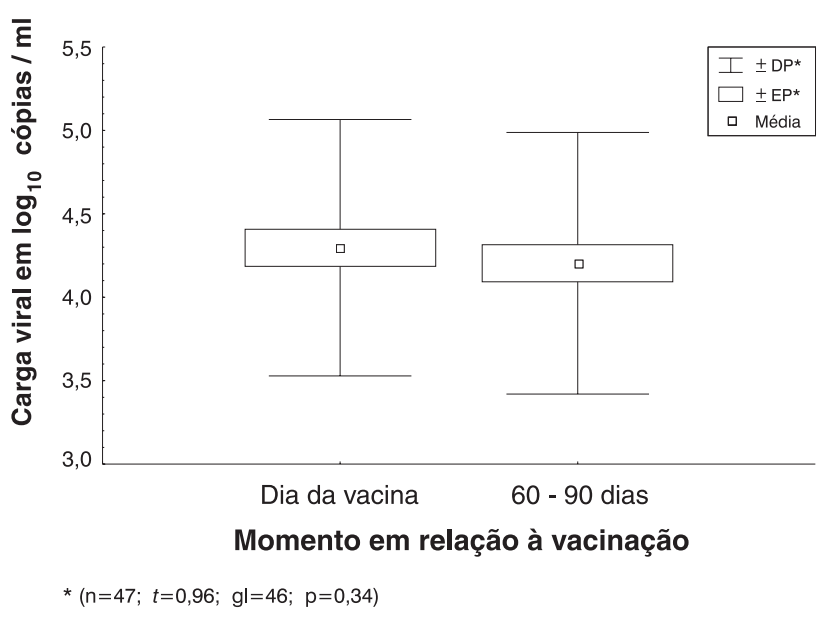

* $\mathrm{CV}=$ carga viral; $\mathrm{n}=$ número de casos; $t=t$ de Student; $g \mathrm{l}=$ graus de liberdade; $\mathrm{DP}=$ desvio padrão; $\mathrm{EP}=$ erro padrão

Figura 3 - Comparação entre os níveis de carga viral do HIV em $\log _{10}$ cópias/ml no dia da vacinação contra influenza, e após 14 a 20, e entre o dia da vacinação e após 60 a 90 dias (Teste $t$ de Student para amostras dependentes) - HIJG

A introdução de medicamentos ARV para uma criança de dois anos e nove meses de idade foi devida à redução nos níveis de linfócitos T CD4+e ao aumento da carga viral do HIV, ambos com variação considerável após a aplicação da vacina, sendo que essa criança permaneceu clinicamente bem, na categoria clínica A.

Não se observou qualquer alteração clínica subseqüentemente à aplicação da vacina em 39 crianças $(76,5 \%)$. Entre as crianças que apresentaram alguma sintomatologia, relatou-se, mais freqüentemente, tosse leve, em seis crianças $(11,8 \%)$, coriza, em três $(5,9 \%)$ e febre cinco dias após a aplicação da vacina em uma criança $(2,0 \%)$. Dois pacien- tes $(3,9 \%)$ apresentaram quadros de broncopneumonia, um deles após um mês da aplicação da vacina, o qual evidenciou inclusive redução na carga viral do HIV e aumento na porcentagem de linfócitos T CD4+, e o outro após dois meses, no qual não houve alteração nos níveis de carga viral ou de linfócitos T CD4+. Esse último paciente apresentava carga viral basal elevada. Observou-se, ainda, estomatite em uma criança $(2,0 \%) 15$ dias após a vacinação, que também evidenciava níveis basais elevados de carga viral, não demonstrando alteração posterior nesses níveis, assim como nos níveis de linfócitos T CD4+.
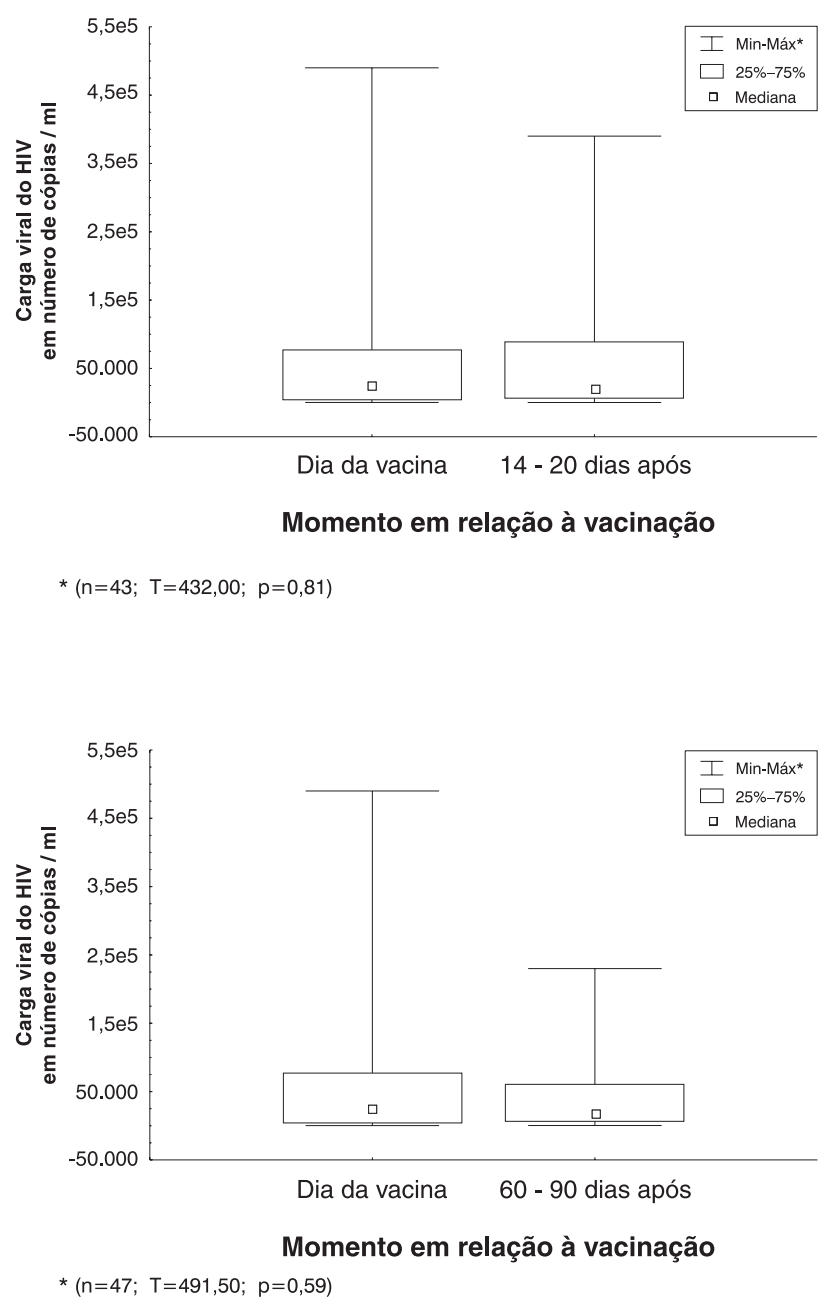

*CV= carga viral; $\mathrm{n}=$ número de casos; $\mathrm{T}=$ teste de Wilcoxon; mín.= mínimo; máx.= máximo

Figura 4 - Comparação entre os níveis de carga viral do HIV em número de cópias/ml no dia da vacinação contra influenza, e após 14 a 20, e entre o dia da vacinação e após 60 a 90 dias (Teste não paramétrico de Wilcoxon para amostras pareadas) - HIJG, Florianópolis, SC 


\section{Discussão}

A situação prática de uma desejada estimulação antigênica significante ocorre durante a administração rotineira das vacinas, sendo que a possibilidade de um aumento da replicação do HIV, mediante a estimulação imunológica induzida por vacinas, é particularmente relevante em crianças infectadas pelo vírus ${ }^{30}$.

Há controvérsias a respeito do aumento ou não da carga viral do HIV induzida pela estimulação imunológica determinada pela utilização de algumas vacinas. Em pediatria, os poucos estudos a respeito levam a uma preocupação bem maior, uma vez que se utiliza uma gama enorme de vacinas $^{31}$.

$\mathrm{O}$ vírus influenza, importante agente etiológico de infecções respiratórias, pode levar em indivíduos imunocompetentes, a um risco de complicações de até $25 \%$. A literatura ainda é escassa com relação a maior gravidade e complicações dessa infecção em portadores do $\mathrm{HIV}^{14}$. O risco aumentado para complicações tem sido aventado por alguns autores, tanto em adultos quanto em crianças infectadas pelo $\mathrm{HIV}^{2,4,32-37}$.

A relação entre o risco e o benefício da utilização da vacina contra a influenza para os pacientes portadores de infecção pelo HIV deve ser considerada, devendo-se levar em conta o risco desses pacientes adquirirem influenza, a história natural dessa infecção nos pacientes infectados pelo HIV, e a morbidade e mortalidade associada ${ }^{38}$.

Apesar da não evidência de uma significância estatística na redução dos níveis percentuais de linfócitos T CD4+ na presente série, 14 a 20 dias após a aplicação do imunobiológico houve uma redução significativa nos valores absolutos $(\mathrm{p}=0,0001)$. Mesmo considerando-se que os valores percentuais são melhores indicadores para a população pediátrica, observa-se uma tendência à redução dos níveis de linfócitos T CD4+ sob a estimulação imunológica induzida pela vacina contra influenza. Se, por um lado, essa observação é preocupante, por outro, se houve estimulação imunológica, significa que o organismo teve capacidade de responder à aplicação do imunobiológico.

Quatorze a vinte dias após a aplicação da vacina contra influenza, observou-se uma redução de pelo menos $20 \%$ em relação aos níveis iniciais de linfócitos T CD4+ em 31,8\% das crianças, sendo que desses, houve uma reversão em $61,5 \%$. Isso evidencia que, mesmo aparentemente transitória na maior parte dos pacientes, a redução dos níveis de linfócitos T CD4+ pode persistir em algumas crianças, tornando-se importante uma monitorização mais rigorosa, tanto do ponto de vista clínico quanto laboratorial.

A redução nos níveis de linfócitos T CD4+ após a vacinação contra influenza, observada em alguns estu$\operatorname{dos}^{8,39}$, não se repetiu na presente série, quando se analisaram os níveis percentuais. A comparação da resposta dos linfócitos T CD4+ após a vacinação contra influenza, entre alguns estudos realizados com pacientes adultos e a presente série, pode ser observada na Tabela 4.
Um dos primeiros estudos com crianças avaliando-se a resposta à vacina contra a influenza em indivíduos portadores do HIV incluiu quatro crianças e oito adultos assintomáticos, que não estavam recebendo qualquer medicação ARV, não sendo analisado separadamente a população pediátrica. Os níveis de linfócitos T CD4+ permaneceram estáveis quatro semanas após a aplicação da vacina ${ }^{40}$.

Os resultados encontrados por Jackson et al. (1997) ${ }^{41}$, em que foram estudadas 53 crianças portadoras do HIV vacinadas contra influenza, demonstraram que a contagem de linfócitos T CD4+ não variou significativamente antes e após a vacinação.

Donovan et al. (1997) ${ }^{37}$, estudando 39 crianças infectadas pelo HIV, constataram que a porcentagem mediana de linfócitos T CD4+ antes da vacinação contra influenza foi de $30 \%$, e após, de $29 \%$ ( $\mathrm{p}=0,86$ ). Os pesquisadores concluíram que não houve evidência de significantes modificações na contagem de linfócitos T CD4+.

Como se pode verificar, as alterações nos níveis de linfócitos T CD4+ observadas no presente estudo concordam com os estudos realizados em crianças, visualizados na Tabela 5, quanto à não ocorrência de alteração nos valores percentuais.

Constatou-se, na presente série, que não houve diferença estatisticamente significativa nos níveis da carga viral do HIV anteriormente e após a utilização da vacina contra influenza, tanto nos níveis em número de cópias $/ \mathrm{ml}(\mathrm{p}=0,99)$ como em $\log _{10}$ cópias $/ \mathrm{ml}(\mathrm{p}=0,98)$. Essa diferença também não foi observada quando se compararam dois momentos entre si, o primeiro com o segundo, em número de cópias $/ \mathrm{ml}$ $(\mathrm{p}=0,81)$ e em $\log _{10}$ cópias $/ \mathrm{ml}(\mathrm{p}=0,69)$, e o primeiro com o terceiro, em número de cópias $/ \mathrm{ml}(\mathrm{p}=0,59)$, e em $\log _{10}$ cópias $/ \mathrm{ml}(\mathrm{p}=0,34)$.

À primeira vista poderíamos dizer que a vacina contra influenza não alteraria os níveis de carga viral do HIV. Quando observamos, no entanto, que oito $(18,2 \%)$ de 44 crianças tiveram uma elevação considerada valorizável $\left(\geq 0,5 \log _{10}\right.$ cópias $/ \mathrm{ml}$ para os maiores de dois anos de idade ou $\geq 0,7 \log _{10}$ para aqueles com idade $\leq$ dois anos) não podemos deixar de analisar mais detalhadamente esse achado.

É imperativo, pois, verificar se essa alteração foi apenas transitória. Constatou-se na terceira determinação que três dessas crianças $(6,8 \%)$ permaneceram com carga viral elevada, quatro apresentaram níveis inclusive inferiores aos iniciais, sendo que em um desses pacientes foi introduzida terapêutica ARV, e em uma criança o nível foi equivalente ao inicial.

Talvez essa elevação da carga viral pudesse ser controlada nos pacientes que estivessem utilizando terapêutica ARV. A preocupação principal seria com aquelas crianças que apresentassem indicação para o início de terapêutica, ou que a indicação pudesse estar sendo considerada, segundo as orientações do Ministério da Saúde do Brasil $(2001)^{18}$, mas que por algum motivo ainda não tivesse sido iniciada. 
Tabela 4 - Estudos em adultos portadores do HIV, avaliando os efeitos da vacinação contra influenza sobre os níveis de LT CD4+ e CV, comparando-os com o presente estudo

\begin{tabular}{|c|c|c|c|c|}
\hline Autores & Desenho & Casuística & LT CD4+ & CV do HIV \\
\hline Presente estudo & $\mathrm{P}$ & 51 crianças & $\begin{array}{l}\text { Redução no } \mathrm{n}^{\circ} \\
(\mathrm{p}=0,0001) \\
\% \text { inalterada } \\
(\mathrm{p}=0,2214)\end{array}$ & $\begin{array}{l}\text { Elevação: } 8 / 44(18,2 \%) \\
\text { Transitório: } 4 / 44(9,1 \%) \\
\text { Não diferença na CV } \\
(p=0,6887 \text { e } 0,8073)\end{array}$ \\
\hline $\begin{array}{l}\text { Huegsberg et al. } \\
(\mathbf{1 9 9 5})^{43}\end{array}$ & $\mathrm{P}, \mathrm{C}$, não $\mathrm{R}$ & $\begin{array}{l}44 \text { adultos HIV+ } \\
16 \text { adultos HIV- }\end{array}$ & Inalterado & - \\
\hline $\begin{array}{l}\text { Glesby et al. } \\
(1996)^{8}\end{array}$ & $\mathrm{P}, \mathrm{R}, \mathrm{D}-\mathrm{C}, \mathrm{C}, \mathrm{Pl}$ & $\begin{array}{l}42 \text { adultos } \mathrm{HIV+:} \\
28 \text { vacinados } \\
14 \text { placebo }\end{array}$ & $\begin{array}{l}\text { Redução nos } \\
2 \text { grupos }\end{array}$ & Inalterada \\
\hline $\begin{array}{l}\text { Rosok et al. } \\
(1996)^{7}\end{array}$ & $\mathrm{P}, \mathrm{C}$ & $\begin{array}{l}10 \text { adultos HIV + } \\
5 \text { controles HIV - }\end{array}$ & - & $\begin{array}{l}\text { Elevação: } 4(40,0 \%) \\
\text { Transitória: } 4(40,0 \%)\end{array}$ \\
\hline $\begin{array}{l}\text { Fowke et al. } \\
(1997)^{44}\end{array}$ & $\mathrm{P}, \mathrm{C}$ & $\begin{array}{l}34 \text { adultos HIV + } \\
9 \text { controles HIV - }\end{array}$ & & $\begin{array}{l}\text { Inalterado } \\
\text { Elevação: } 6 / 32(18,8 \%)\end{array}$ \\
\hline $\begin{array}{l}\text { Tasker et al. } \\
(\mathbf{1 9 9 8})^{39}\end{array}$ & $\mathrm{R}, \mathrm{D}-\mathrm{C}, \mathrm{C}, \mathrm{Pl}$ & $\begin{array}{l}47 \text { adultos HIV +: } \\
23 \text { vacinados } \\
24 \text { placebo }\end{array}$ & $\begin{array}{l}\text { Redução no } \\
\text { grupo vacinado }\end{array}$ & $\begin{array}{c}\text { Elevação: } 1 \text { a } 2 \text { sem.: } \\
\text { Vac. 5/20 }(25,0 \%) \\
\text { Plac. 1/24 }(4,2 \%) \\
\text { Elevação: } 4 \text { a } 6 \text { sem.: } \\
\text { Vac. 14/20 }(70 \%) \\
\text { Plac.: 8/24 (35\%) }\end{array}$ \\
\hline $\begin{array}{l}\text { Fuller et al. } \\
(1999)^{38}\end{array}$ & $\mathrm{P}$ & 49 adultos & - & $\begin{array}{l}\text { Elevação: } 6(12,2 \%) \\
\text { Transitória: } 3(6,1 \%)\end{array}$ \\
\hline $\begin{array}{l}\text { Günthard et al. } \\
(2000)^{9}\end{array}$ & $\mathrm{P}, \mathrm{C}$ & $\begin{array}{l}19 \text { adultos HIV + } \\
5 \text { controles HIV - }\end{array}$ & Inalterado & $\begin{array}{l}\text { Elevação: } 10(52,6 \%) \\
\text { Transitória: } 4(21,1 \%)\end{array}$ \\
\hline
\end{tabular}

$\mathrm{P}=$ prospectivo; $\mathrm{R}=$ randomizado; $\mathrm{C}=$ controlado, $\mathrm{D}-\mathrm{C}=$ duplo cego; $\mathrm{Pl}=$ placebo; $\mathrm{LT}=$ linfócito $\mathrm{T} ; \mathrm{CV}=$ carga viral do $\mathrm{HIV}$; sem.= semanas; Vac. $=$ grupo vacinado; Plac.$=$ grupo placebo.

Essas crianças poderiam estar mais vulneráveis aos efeitos deletérios de uma elevação da carga viral do HIV, mesmo que transitória.

Apenas uma das sete crianças que não vinham recebendo qualquer medicamento ARV, no presente estudo, apresentou aumento considerável na carga viral do HIV, de 14 a 20 dias após a aplicação da vacina.

As mudanças transitórias na carga viral após a utilização de vacinas poderiam ser interpretadas como deterioração do estado clínico do paciente, levando a modificações desnecessárias ou contraproducentes nos regimes terapêu$\operatorname{ticos}^{31}$.

A comparação entre os resultados observados na presente série em relação às alterações na carga viral do HIV após a vacinação contra influenza, com alguns estudos realizados em adultos e em crianças, pode ser visualizada nas Tabelas 4 e 5 . As séries constituídas por pacientes na faixa etária pediátrica são mais restritas e com menores números de pacientes.
Utilizando-se PCR quantitativo para a avaliação da carga viral do HIV, Ramilo et al. (1996) ${ }^{30}$ estudaram 16 crianças infectadas pelo vírus, com idade entre seis meses e 14 anos, vacinadas contra influenza. Esses autores evidenciaram uma elevação substancial na carga viral em cinco $(33,3 \%)$ de 15 pacientes, cujo número aumentou mais de $150 \%$, muito além da variabilidade de $20 \%$ a $30 \%$ estimada pelo ensaio, e em quatro desses pacientes a carga viral retornou aos níveis basais de seis a oito semanas após. Os pesquisadores concluíram que, em decorrência da pequena casuística, não foi possível uma análise estatística detalhada dos resultados, não se podendo avaliar se as modificações na carga viral tiveram significância clínica.

Entre as 53 crianças estudadas por Jackson et al. (1997) $)^{41}$, 50 delas recebendo terapia ARV, 40 vacinadas no ano anterior contra influenza, 13 em uso mensal de imunoglobulina endovenosa, obteve-se amostra de soro com menos de quatro semanas em apenas 14 crianças, observando-se que seis $(11,3 \%)$ tiveram um aumento na carga viral de 
Tabela 5 - Estudos com crianças portadoras do HIV, avaliando os efeitos da vacinação contra influenza sobre os níveis de LT CD4+ e CV, comparando-as com o presente estudo

\begin{tabular}{|c|c|c|c|c|}
\hline Autores & Desenho & Casuística & LT CD4+ & CV do HIV \\
\hline Presente estudo & $\mathrm{P}$ & 51 crianças & $\begin{array}{l}\text { Redução no } n^{\circ} \\
(\mathrm{p}=0,0001) \\
\% \text { inalterada } \\
(\mathrm{p}=0,2214)\end{array}$ & $\begin{array}{l}\text { Elevação: } 8 / 44(18,2 \%) \\
\text { Transitório: } 4 / 44(9,1 \%) \\
\text { Não diferença na CV } \\
(p=0,6887 \text { e } 0,8073)\end{array}$ \\
\hline $\begin{array}{l}\text { Yerly et al. } \\
(1994)^{40}\end{array}$ & $\mathrm{P}, \mathrm{C}$ & $\begin{array}{l}8 \text { adultos } \\
4 \text { crianças }\end{array}$ & Inalterado & Inalterada \\
\hline $\begin{array}{l}\text { Ramilo et al. } \\
(1996)^{30}\end{array}$ & $\mathrm{P}$ & 16 crianças & - & $\begin{array}{l}\text { Elevação: } 5 / 15(33,3 \%) \\
\text { Transitória: } 4 / 15(26,7 \%)\end{array}$ \\
\hline $\begin{array}{l}\text { Jackson et al. } \\
(1997)^{41}\end{array}$ & $\mathrm{P}$ & 53 crianças & Inalterado & Elevação: 6/53 (11,3\%) \\
\hline $\begin{array}{l}\text { Donovan et al. } \\
(1997)^{31}\end{array}$ & $\mathrm{P}$ & 39 crianças & Inalterado & $\begin{array}{l}\text { Elevação de } 4 \text { vezes: } \\
1(2,5 \%)\end{array}$ \\
\hline $\begin{array}{l}\text { Hanekon et al. } \\
(2000)^{42}\end{array}$ & P, R, D-C, vit. A & 50 crianças & - & $\begin{array}{l}\text { Elevação: } 24(48,0 \%) \\
\text { Transitória: } 11(45,8 \%)\end{array}$ \\
\hline
\end{tabular}

$\mathrm{P}=$ prospectivo; $\mathrm{R}=$ randomizado; $\mathrm{C}=$ controlado, $\mathrm{D}-\mathrm{C}=$ duplo cego; $\mathrm{Pl}=$ placebo; $\mathrm{LT}=$ linfócito $\mathrm{T} ; \mathrm{CV}=$ carga viral do $\mathrm{HIV} ;$ sem $=$ semanas; $\mathrm{Vac} .=$ grupo vacinado; Plac. $=$ grupo placebo.

0,3 $\log _{10}$ cópias/ml ou mais. Os autores discutem que a não observação, nesse estudo, de alterações significativas na carga viral poderia estar refletindo a ação concomitante da terapia ARV, e concluem que a vacinação contra influenza em crianças portadoras do HIV parece segura, havendo alguma resposta de anticorpos, recomendando-se sua utilização de rotina. A evidência de um aumento prolongado nos níveis séricos da carga viral não foi observada, e se elevações transitórias ocorreram, essas não apresentaram consequiências clínicas preocupantes.

Somente uma das 39 crianças incluídas no estudo de Donovan et al. (1997) ${ }^{31}$ teve um aumento superior a quatro vezes nos níveis basais de carga viral, após a vacinação contra influenza. Os resultados, segundo os pesquisadores, não excluiriam a possibilidade de um aumento transitório na carga viral nas primeiras semanas após a vacinação.

O estudo de Hanekon et al. (2000) ${ }^{42}$ com 59 crianças infectadas pelo HIV, todas em uso de terapia anti-retroviral, foi realizado para verificar uma possível interferência da utilização prévia de vitamina $\mathrm{A}$ na resposta sorológica à vacina contra influenza, e se essa vitamina poderia modular possíveis alterações na carga viral, decorrentes da estimulação imunológica da vacina. Demonstrou-se que a carga viral do momento da vacinação ao dia 14, avaliando-se 50 pacientes (sete excluídos por mudança na terapêutica ARV e dois por dados incompletos), permaneceu estável em seis
$(12,0 \%)$, diminuiu em $20(40,0 \%)$ e aumentou em 24 $(48 \%)$, dos quais $13(54,2 \%)$ ainda tinham níveis acima dos basais no dia 28 (média de aumento até o dia 28 de $0,5 \pm 0,1$ $\log _{10}$ cópias/ml), e nos 11 restantes $(45,8 \%)$, retornou aos níveis basais. Os autores concluíram que a vacinação contra influenza em crianças portadoras do HIV realmente pode levar a um aumento na carga viral, diferindo de alguns trabalhos, os quais tinham uma amostra menor, não utilizaram testes tão sensíveis, e os momentos de detecção do aumento podem ter sido diferentes.

O estudo desenvolvido na presente pesquisa permitiu chegar-se às seguintes conclusões: (a) não houve diferença estatisticamente significativa nos níveis da carga viral do HIV entre o momento da aplicação da vacina, 14 a 20 dias e 60 a 90 dias após sua administração (p=0,98); (b) apesar de não ocorrer diferença estatisticamente significativa nos níveis da carga viral, antes e após a aplicação da vacina, oito pacientes tiveram um aumento $\geq 0,5 \log _{10}$ cópias/ml de 14 a 20 dias após sua utilização, sendo que em três $(6,8 \%)$, os níveis permaneceram elevados 60 a 90 dias após; (c) não se observou diferença estatisticamente significativa nos níveis séricos percentuais de linfócitos T CD4+, na avaliação simultânea entre o momento da vacinação e os dois subseqüentes ( $\mathrm{p}=0,45)$; (d) não se observou diferença estatisticamente significativa na avaliação dos níveis séricos percentuais de linfócitos T CD4+, em separado, entre o dia da 
aplicação da vacina e 14 a 20 dias após $(\mathrm{p}=0,22)$, e entre o dia da aplicação da vacina e 60 a 90 dias após ( $\mathrm{p}=0,75$ ); (e) houve diferença estatisticamente significativa $(\mathrm{p}=0,002)$ entre os valores absolutos de linfócitos T CD4+, comparando-se, simultaneamente, as aferições no dia da imunização contra influenza e as duas posteriores; (f) evidenciou-se redução estatisticamente significativa na avaliação dos valores absolutos de linfócitos T CD4+, em separado, entre a primeira e a segunda aferição $(\mathrm{p}=0,0001)$, o mesmo não se mantendo entre a primeira e terceira $(\mathrm{p}=0,16)$.

Apesar da casuística pequena do presente estudo de pacientes que não estavam utilizando medicamentos antiretrovirais, aparentemente não houve correlação entre a elevação da carga viral do HIV e redução dos níveis de linfócitos T CD4+ com a não utilização dos medicamentos.

Embora possam ocorrer elevações na carga viral do HIV e redução nos níveis de linfócitos T CD4+ após a vacinação contra influenza, sua utilização tem se mostrado segura, recomendando-se uma certa prudência nas crianças com a condição clínica e imunológica não estável, principalmente se estas não estiverem em terapêutica anti-retroviral eficaz.

Os profissionais que prestam atenção à saúde dos pacientes portadores do HIV devem estar atentos para a não supervalorização de achados laboratoriais isolados, especialmente na população pediátrica, cujos parâmetros de normalidade ou de pontos de corte muitas vezes não estão estabelecidos. A repetição de alguns exames complementares pode ser recomendada em algumas situações antes que se modifique a terapêutica, ou que se submeta o paciente a procedimentos que possam ser desnecessários.

A não disponibilidade ou escassez de testes laboratoriais pode se constituir em um fator limitante, entretanto, uma boa avaliação clínica pode, com bastante precisão, esclarecer algumas situações de dúvida.

As investigações a respeito dos efeitos das vacinas sobre o sistema imunológico de crianças e adultos portadores do HIV devem prosseguir, não somente no sentido de se verificar possíveis interferências nos níveis de linfócitos T CD4+ ou na carga viral, mas também na resposta sorológica, na duração da imunidade e na necessidade de doses adicionais ou de revacinação após a reconstituição imunológica em pacientes com terapêutica ARV potente.

\section{Agradecimentos}

À equipe multiprofissional do Serviço de Assistência Especializada e Hospital-Dia do Hospital Infantil Joana de Gusmão; ao Laboratório Central do Estado de Santa Catarina; à engenheira e estatística Sílvia Modesto Nassar, pela orientação na análise estatística, e ao Centro de Pós-graduação da Faculdade de Medicina da UFMG.

\section{Referências bibliográficas}

1. Andiman WA, Shearer WT. Lymphoid interstitial pneumonitis. In: Pizzo PA, Wilfert CM, editores. Pediatric AIDS, the challenge of HIV infection in infants, children, and adolescents. $3^{\mathrm{a}}$ ed. Baltimore: Williams and Wilkins; 1998.p.323-34.

2. Englund JA, King. JC Jr. Respiratory viral infections in children infected with HIV. In: Pizzo PA, Wilfert CM, editores. Pediatric AIDS, the challenge of HIV infection in infants, children, and adolescents. $3^{\text {a }}$ ed. Baltimore: Williams and Wilkins; 1998. p.227-49.

3. Bukrinsky MI, Stanwick TL, Dempsey MP, Stevenson M. Quiescent T lymphocytes as an inducible virus reservoir in HIV1 infection. Science 1991;254:423-7.

4. Chadwick EG, Chang G, Decker MD, Yogev R, Dimichele D, Edwards KM. Serologic response to standard inactivated influenza vaccine in human immunodeficiency virus-infected children. Pediatr Infect Dis J 1994;13:206-11.

5. Lyall EGH, Charlett A, Watkins P, Zambon M. Response to influenza virus vaccination in vertical HIV infection. Arch Dis Child 1997;76:215-18.

6. Rosenberg ZF, Fauci AS. Minireview: induction of expression of HIV in latently or chronically infected cells. AIDS Res Hum Retroviruses 1989;5:1-4.

7. Rosok B, Voltersvik P, Bjerknes R, Axelssons M, Haaheim LR, Asjö B. Dynamics of HIV-1 replication following influenza vaccination of HIV+ individuals. Clin Exp Immunol 1996;104:203-7.

8. Glesby MJ, Hoover DR, Farzadegan H, Margolick JB, Saah AJ. The effect of influenza vaccination on human immunodeficiency virus type 1 load: randomized, double-blind, placebo-controlled study. J Infect Dis 1996;174:1332-6.

9. Günthard HF, Wong JK, Spina CA, Ignacio C, Kwok S, Christopherson $\mathrm{C}$, et al. Effect of influenza vaccination on viral replication and immune response in persons infected with human immunodeficiency virus receiving potent antiretroviral therapy. J Infect Dis 2000;181:522-31.

10. Shearer WT, Quinn TC, LaRussa P, Lew JF, Mofenson L, Almy $S$, et al. Viral load and disease progression in infants infected with human immunodeficiency virus type 1 . N Engl J Med 1997;336:1337-42.

11. Palumbo PE, Raskino C, Fiscus S, Pahwa S, Fowler MG, Spector AS, et al. Predictive value of quantitative plasma HIV RNA and CD4+ lymphocyte count in HIV-infected infants and children. JAMA 1998;279:756-61.

12. Biggar RJ, Janes M, Pilon R, Miotti P, Taha TET, Broadhead R, et al. Virus levels in untreated African infants infected with human immunodeficiency virus type 1. J Infect Dis 1999;180: 1838-43.

13. Centers for Diseases Control and Prevention - CDC. Recommendations of the Immunization Practices Advisory Committee (ACIP). Prevention and control of influenza: part 1, vaccines. MMWR 1989;38:297-311.

14. American Academy of Pediatrics. Human immunodeficiency virus infection. In: 2000 Red Book: Report of the Committee on Infectious Diseases. 25 a ed. Elk Grove Village, IL: American Academy of Pediatrics; 2000.p.325-50.

15. Modlin JF, Snider DE, Brooks DA, Clover RD, Deseda-Tous J, Helms CM, et al. Prevention and control of influenza: recommendations of the Advisory Committee on Immunization Practices. MMWR 2001;50:RR04:1-46.

16. Brasil. Ministério da Saúde. Coordenação Nacional de DST e Aids. Guia de Tratamento Clínico da Infecção pelo HIV em Crianças. Série Normas e Manuais Técnicos. $\mathrm{n}^{\circ}$ 102. Brasília, 2000. 44p. 
17. Brasil. Ministério da Saúde. Fundação Nacional de Saúde. Programa Nacional de Imunizações. Centros de Referência de Imunobiológicos Especiais. Imunobiológicos Especiais e suas Indicações. Brasília, 1999-2000.

18. Brasil. Ministério da Saúde. Coordenação Nacional de DST e Aids. Guia de Tratamento Clínico da Infecção pelo HIV em Crianças. Série Normas e Manuais Técnicos. Brasília, 2001. $38 \mathrm{p}$.

19. Brasil. Ministério da Saúde. Coordenação Nacional de DST e Aids. Guia de Tratamento Clínico da Infecção pelo HIV em Crianças. Brasília, 1999.

20. Centers for Diseases Control and Prevention - CDC. 1994 Revised classification system for human immunodeficiency virus infection in children less than 13 years of age. MMWR 1994;43(RR-12):12-19.

21. Organon Teknica. NucliSensä, NASBA diagnostics, HIV-1 QT reagentes para amplificação de ácidos nucléicos. Organon Teknica BV, Boxtel, Holanda.

22. Brasil. Ministério da Saúde. Coordenação Nacional de DST e Aids. Carga Viral. Brasília, 1999. 94p.

23. Centers for Diseases Control and Prevention - CDC. Guidelines for the use of antiretroviral agents in pediatric HIV infection. MMWR 1998;47(RR-4):1-44.

24. Brasil. Ministério da Saúde. Coordenação Nacional de DST e Aids. Manual de Contagem de Linfócitos T CD4+. Brasília, 1998. 110p.

25. Pasteur Mérieux Connaught. Rhône-Poulenc Group. Vaxigrip Cepas 98-99. Vacina inativada contra gripe; virus fragmentados.

26. Centers for Diseases Control. Prevention and control of influenza: Recommendations of the Advisory Committee on Immunization Practices. MMWR 1999;48:1-28.

27. Dean AG, Dean JA, Coulombier D, Brendel KA, Smith DC, Burton AH et al. Epi Info, version 6.04d. A word-processing, database, and statistics program for public health on IBMcompatible microcomputers. Centers for Diseases Control and Prevention, Atlanta, Georgia, U.S.A., 1995, revised 1998.

28. Microsoft Brasil. Microsoft Office, Excel for Windows, versão 2000. Stat Soft. Statistica 5.1, 1998 ed.

29. Ramilo O, Hicks PJ, Borvak J, Gross LM, Zhong D, Squires JE, et al. $\mathrm{T}$ cell activation and human immunodeficiency virus replication after influenza immunization of infected children. Pediatr Infect Dis J 1996;15:197-203.

30. Maldarelli F, McPhee J, Ellner P, Neu HC. Influenza in HIVexposed adults [resumo]. Clin Res 1988;36:800A.

31. Donovan RM, Moore E, Bush CE, Markowitz NP, Saravolatz LD. Changes in plasma HIV RNA levels and CD4 cell counts after vaccination of pediatric patients. AIDS 1997;11:1054-6.

32. Maldarelli F, McPhee J, Ellner P, Neu HC. Influenza in HIVexposed adults[resumo]. Clin Res 1988;36:800A.

33. Safrin S., Rush J.D., Mills J. Influenza in patients with human immunodeficiency virus infection. Chest 1990;98: 33-7.

34. Cohen-Abbo A, Wright PF. Complex etiology of pneumonia in infants perinatally infected with human immunodeficiency virus 1. Ped Infect Dis J 1991;10:545-47.
35. Serwint JR, Miller RM, Korsch BM. Influenza type A and B infections in hospitalized pediatric patients. Am J Dis Child 1991;145:623-6.

36. Izurieta HS, Thompson WW, Kramarz P, Shay DK, Davis RL, DeStefano F, et al. Influenza and the rates of hospitalization for respiratory disease among infants and young children. $\mathrm{N}$ Engl $\mathrm{J}$ Med 2000;342:232-9.

37. Preboth M. Advisory Committee on Immunization Practices issues recommendation for the 2000-2001 influenza season. Am Fam Physician 2000;62:233-6.

38. Fuller JD, Craven DE, Steger KA, Cox N, Heeren TC, Chernoff D. Influenza vaccination of human immunodeficiency virus (HIV)-infected adults: impact on plasma levels of HIV type 1 RNA and determinants of antibody response. Clin Infect Dis 1999;28:541-7.

39. Tasker SA, O’Brien WA, Treanor JJ, Weiss PJ, Olson PE, Kaplan AH, Wallace MR. Effects of influenza vaccination in HIV-infected adults: a double-blind, placebo-controlled trial. Vaccine 1998;16:1039-42.

40. Yerly S, Wunderli W, Wyler CA, Kaiser L, Hirschel B, Suter S, et al. Influenza immunization of HIV-1-infected patients does not increase HIV-1 viral load. AIDS 1994;8:1503-4.

41. Jackson CR, Vavro CL, Valentine ME, Pennington KN, Lanier ER, Katz SL, et al. Effect of influenza immunization on immunologic and virologic characteristics of pediatric patients infected with human immunodeficiency virus. Ped Infect Dis J 1997; 16:200-4.

42. Hanekon WA, Yogev R, Heald LM, Edwards KM, Hussey GD, Chadwick EG. Effect of vitamin A therapy on serologic responses and viral load changes after influenza vaccination in children infected with the human immunodeficiency virus. J Pediatr 2000;136:550-2.

43. Huengsberg M, Chakraverty MP, Cooper G, Shahmanesh M. Response to influenza immunization in asymptomatic HIV infected men. Genitourin Med 1995;71:355-7.

44. Fowke KR, D'Amico R, Chernoff DN, Pottage JC Jr, Benson $\mathrm{CA}$, Sha BE, et al. Immunologic and virologic evaluation after influenza vaccination of HIV-1-infected patients. AIDS 1997;11:1013-21.

Endereço para correspondência:

Dr. Aroldo Prohmann de Carvalho

Rua dos Cações, 106 - Jurerê Internacional

CEP 88053-475 - Florianópolis, SC

Fone: (48) 282.1690 - Fax: (48) 251.9099

E-mail: aroldopc@uol.com.br 